\title{
Interface studies of tungsten nitride and titanium nitride composite metal gate electrodes with thin dielectric layers
}

\author{
B. Claflin, ${ }^{\text {a) }}$ M. Binger, and G. Lucovsky \\ Department of Physics, North Carolina State University, Raleigh, North Carolina 27695-8202
}

(Received 1 December 1997; accepted 16 March 1998)

\begin{abstract}
Interface formation between reactively sputtered tungsten nitride $\left(\mathrm{WN}_{x}\right)$ or titanium nitride $\left(\mathrm{TiN}_{x}\right)$ metallic films and thermally grown silicon dioxide $\left(\mathrm{SiO}_{2}\right)$ layers is studied by interrupted growth with on-line Auger electron spectroscopy. For both composite metals, growth proceeds directly without a metal precursor layer. The chemical stability of these $\mathrm{WN}_{x} / \mathrm{SiO}_{2}$ and $\mathrm{TiN}_{x} / \mathrm{SiO}_{2}$ interfaces is investigated by rapid thermal annealing up to $850{ }^{\circ} \mathrm{C}$. The $\mathrm{WN}_{x} / \mathrm{SiO}_{2}$ interface is stable up to $650{ }^{\circ} \mathrm{C}$ while $\mathrm{TiN}_{x} / \mathrm{SiO}_{2}$ is stable below $850^{\circ} \mathrm{C}$. Metal-oxide-semiconductor capacitors have been fabricated with $\mathrm{WN}_{x}$ and $\mathrm{TiN}_{x}$ gates and $7.5 \mathrm{~nm}$ thick thermal oxide gate dielectrics with interface trap densities, $D_{\mathrm{it}}<2 \times 10^{11} \mathrm{~cm}^{-2} \mathrm{eV}^{-1}$. Capacitance-voltage and current-voltage measurements indicate the Fermi level for $\mathrm{TiN}_{x}$ lies near midgap in $\mathrm{Si}$, while for $\mathrm{WN}_{x}$ it lies closer to the valence band. (C) 1998 American Vacuum Society. [S0734-2101(98)59303-7]
\end{abstract}

\section{INTRODUCTION}

The choice of design parameters for each new generation of complimentary metal-oxide-semiconductor (CMOS) devices relies heavily on the application of scaling laws to the values used in the previous generation of integrated circuits. Several scaling laws ${ }^{1-4}$ have been proposed to address particular design issues while providing flexibility in the selection of other device parameters. In general, these scaling laws produce shorter channels, thinner dielectric layers, shallower source and drain junctions, reduced operating voltages, and heavier channel doping. These requirements impose demanding specifications on the choice of gate electrode material, thus creating significant technological challenges to the continued use of heavily doped polycrystalline silicon (poly$\mathrm{Si}$ ) for this application. Depletion effects in the poly-Si gate electrode and the corresponding voltage drop become more significant for smaller devices and may destroy the targeted scaling performance.

Metals and metal alloys are attractive as alternative gate electrode materials because they do not suffer from depletion effects. However, these materials may suffer from problems due to diffusion or reactivity with the gate dielectric during later processing steps. In particular, many transition metals either exhibit poor adhesion or chemically react with $\mathrm{SiO}_{2}$ at elevated temperatures resulting in the formation of a silicide layer covered by a metal oxide. 5,6

Recently, several groups ${ }^{7-15}$ have investigated $\mathrm{TiN}_{x}$ as a potential gate electrode material because it has low resistivity, its work function lies near midgap in $\mathrm{Si}$, and it is frequently used as a diffusion barrier. In this article, on-line Auger electron spectroscopy (AES) is used to examine the initial growth and subsequent evolution of $\mathrm{WN}_{x}$ and $\operatorname{TiN}_{x}$ metallic films deposited by reactive magnetron sputtering on thermal $\mathrm{SiO}_{2}$ dielectric layers. Sequential rapid thermal annealing (RTA) treatments followed by AES measurements are used to monitor the chemical stability of the $\mathrm{WN}_{x} / \mathrm{SiO}_{2}$

${ }^{a}$ Electronic mail: claflin@ncsu.edu and $\mathrm{TiN}_{x} / \mathrm{SiO}_{2}$ interfaces up to $850{ }^{\circ} \mathrm{C}$. Finally, capacitance-voltage $(C-V)$ and current-voltage $(I-V)$ characteristics of metal-oxide-semiconductor (MOS) capacitors employing $\mathrm{WN}_{x}$ and $\mathrm{TiN}_{x}$ gates are presented.

\section{EXPERIMENT}

Thin films of $\mathrm{WN}_{x}$ and $\mathrm{TiN}_{x}$ were deposited at $300 \mathrm{~K}$ by reactive magnetron sputtering of a $99.98 \% \mathrm{~W}$ or $99.9 \% \mathrm{Ti}$ target, respectively, using 99.999\% $\mathrm{Ar}$ and $99.999 \% \mathrm{~N}_{2}$ mixed in a 5:1 ratio and a plasma power of $50 \mathrm{~W}$. Substrates were $3 \mathrm{in}$. Si (100) wafers on which a $5.5 \mathrm{~nm}$ thick thermal oxide was grown. The chamber pressure during deposition was 6 mTorr while the base pressure was $P_{b} \leqslant 2 \times 10^{-9}$ Torr. Under these conditions, average deposition rates of $6 \mathrm{~nm} / \mathrm{min}$ for $\mathrm{WN}_{x}$ and $1 \mathrm{~nm} / \mathrm{min}$ for $\mathrm{TiN}_{x}$ were determined from cross-sectional scanning electron microscope measurements of bulk films.

The formation and evolution of $\mathrm{WN}_{x} / \mathrm{SiO}_{2}$ and $\mathrm{TiN}_{x} / \mathrm{SiO}_{2}$ interfaces were observed by interrupted growth and AES. Several ultrathin layers of $\mathrm{WN}_{x}$ or $\mathrm{TiN}_{x}$ were sequentially deposited and AES spectra collected until the disappearance of the $\mathrm{Si}_{L V V}$ Auger peak at a metal thickness, $d$ $\sim 0.8 \mathrm{~nm}$, indicated that the interface was buried. Thicker layers $(0.5-1.0 \mathrm{~nm}$ each) were then deposited and measured with AES to monitor the development of the $\mathrm{WN}_{x}$ or $\mathrm{TiN}_{x}$ layer, and finally, thick films were prepared to verify bulk characteristics. AES spectra were measured using a model 10-155 PHI cylindrical mirror analyzer at a primary electron energy of $3 \mathrm{keV}$. For reference, bulk W and Ti AES spectra were also collected.

The chemical stability of $\mathrm{WN}_{x} / \mathrm{SiO}_{2}$ and $\mathrm{TiN}_{x} / \mathrm{SiO}_{2}$ interfaces was investigated by on-line rapid thermal annealing. A $0.6-0.7 \mathrm{~nm}$ thick $\mathrm{WN}_{x}$ or $\mathrm{TiN}_{x}$ layer was deposited on $\mathrm{SiO}_{2}$ and annealed for $3 \mathrm{~min}$ in vacuum from 350 to $850{ }^{\circ} \mathrm{C}$ in $100^{\circ} \mathrm{C}$ steps. AES spectra were measured between each annealing treatment.

MOS capacitors were fabricated with $\mathrm{WN}_{x}$ and $\operatorname{TiN}_{x}$ gate electrodes. A field oxide was thermally grown on RCA 


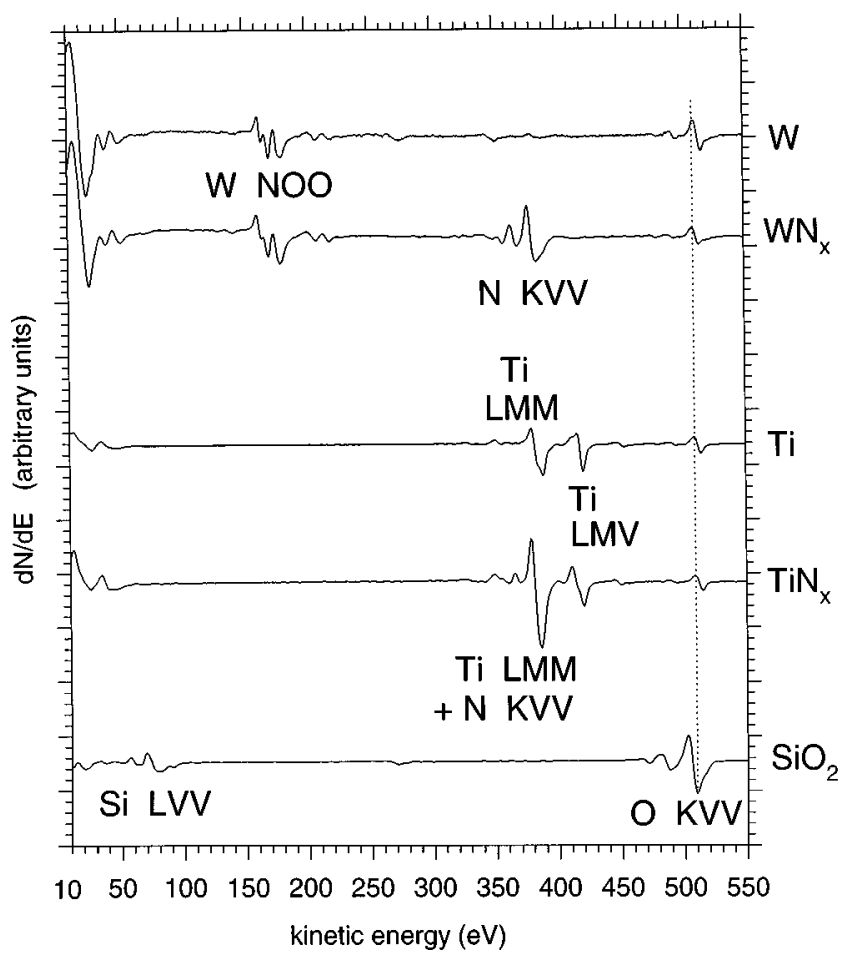

FIG. 1. Derivative AES spectra of bulk $\mathrm{SiO}_{2}, \mathrm{TiN}_{x}, \mathrm{Ti}, \mathrm{WN}_{x}$, and $\mathrm{W}$ films with Auger transitions identified. The $\mathrm{O}_{K V V}$ peak is chemically blueshifted for the metals relative to $\mathrm{SiO}_{2}$.

cleaned $p$-type $\mathrm{Si}(100)$ wafers. Active areas were patterned, wet chemically etched, and another RCA clean performed before a $7.5 \mathrm{~nm}$ thermal gate oxide was grown. The wafers were patterned for lift-off and $50 \mathrm{~nm}$ of $\mathrm{WN}_{x}$ or $\mathrm{TiN}_{x}$ sputtered. A $100 \mathrm{~nm} \mathrm{Al} \mathrm{layer} \mathrm{was} \mathrm{subsequently} \mathrm{sputtered} \mathrm{to} \mathrm{fa-}$ cilitate external contact. After lift-off, Al back-contacts were evaporated and a postmetallization anneal was carried out in $\mathrm{H}_{2}$ at $350{ }^{\circ} \mathrm{C}$ for $30 \mathrm{~min}$. High-frequency and quasistatic $C-V$ measurements were performed in addition to $I-V$ measurements in the Fowler-Nordheim tunneling regime.

\section{RESULTS}

Figure 1 shows derivative AES reference spectra for bulk $\mathrm{SiO}_{2}, \mathrm{~W}, \mathrm{WN}_{x}, \mathrm{Ti}$, and $\mathrm{TiN}_{x}$ films with the relevant spectral features labeled according to the Auger transitions involved. For $\mathrm{TiN}_{x}$, the $\mathrm{Ti}_{L M M}$ and $\mathrm{N}_{K V V}$ features overlap ${ }^{16-19}$ resulting in a peak intensity at $385 \mathrm{eV}$ nearly twice that of the $\mathrm{Ti}_{L M V}$ transition at $420 \mathrm{eV}$. In contrast, for pure Ti these intensities are nearly equal. A small concentration of parasitic oxygen is seen for each of the metallic films, but the $\mathrm{O}_{K V V}$ peak is chemically blueshifted by about $5 \mathrm{eV}$ from its position in $\mathrm{SiO}_{2}$.

Derivative AES spectra of the $\mathrm{WN}_{x} / \mathrm{SiO}_{2}$ interface formation and growth is shown in Fig. 2 as metallic layers are deposited sequentially. The bottom curve shows the bare $\mathrm{SiO}_{2}$ spectrum and subsequent spectra are offset from it corresponding to their integrated $\mathrm{WN}_{x}$ deposition time. The $\mathrm{Si}_{L V V}$ and $\mathrm{O}_{K V V}$ peak intensities decrease rapidly as the first few metallic layers are added while the $\mathrm{W}_{N O O}$ and $\mathrm{N}_{K V V}$

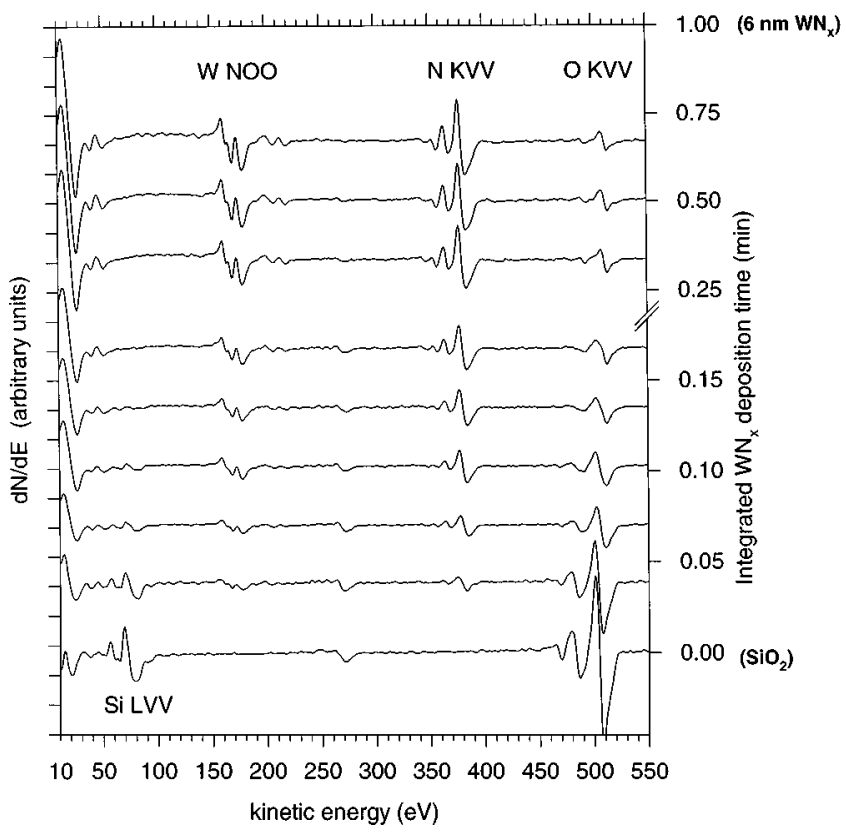

FIG. 2. Interrupted growth of $\mathrm{WN}_{x}$ on $\mathrm{SiO}_{2} \cdot \mathrm{Si}_{L V V}$ and $\mathrm{O}_{K V V}$ intensities decrease while $\mathrm{W}_{N O O}$ and $\mathrm{N}_{K V V}$ peaks increase as additional layers are deposited. The $\mathrm{O}_{K V V}$ peak gradually blueshifts to metal-oxide position as the interface gets buried.

intensities increase. The $\mathrm{O}_{K V V}$ peak also gradually blueshifts to the position characteristic of the metal by the time the $\mathrm{Si}_{L V V}$ signal has completely disappeared, indicating the presence of parasitic oxygen. Additional layers increase the intensity of the $\mathrm{W}$ and $\mathrm{N}$ features until bulk spectra are observed.

Similar AES spectra for the growth of $\mathrm{TiN}_{x}$ on $\mathrm{SiO}_{2}$ are presented in Fig. 3. As was seen for $\mathrm{WN}_{x}$, the $\mathrm{Si}_{L V V}$ and $\mathrm{O}_{K V V}$ intensities decrease while the $\mathrm{Ti}_{L M M}+\mathrm{N}_{K V V}$ and $\mathrm{Ti}_{L M V}$ peaks increase as successive layers of $\mathrm{TiN}_{x}$ are deposited. The $\mathrm{O}_{K V V}$ blueshift is again observed and the intensity of the $\mathrm{Ti}_{L M M}+\mathrm{N}_{K V V}$ peak at $385 \mathrm{eV}$ is seen to be about twice that of the $\mathrm{Ti}_{L M V}$ peak at $420 \mathrm{eV}$ for all spectra.

The chemically stability of the $\mathrm{WN}_{x} / \mathrm{SiO}_{2}$ interface is displayed in Fig. 4 for RTA treatments up to $750{ }^{\circ} \mathrm{C}$. The bottom curve shows the bare $\mathrm{SiO}_{2}$ AES spectrum followed by the as-deposited $\mathrm{WN}_{x}$ layer. To provide the most sensitivity to chemical reactivity at the interface, the minimum metallic layer thickness, $d=0.7 \mathrm{~nm}$, was used such that the $\mathrm{Si}_{L V V}$ peak intensity was reduced to zero as seen. Successive curves were measured after 3 min RTA treatments in vacuum at the temperatures shown. A dramatic change in the spectrum is observed after annealing at $650{ }^{\circ} \mathrm{C}$; the $\mathrm{Si}_{L V V}$ peak reappears, the $\mathrm{O}_{K V V}$ signal increases and redshifts back to the position corresponding to $\mathrm{SiO}_{2}$. At lower temperatures, other subtle changes in intensity are observed particularly for the $\mathrm{O}_{K V V}$ peak. These effects are being studied further but are believed to be due to oxidation from residual gases in the RTA chamber rather than intrinsic to the sample.

Figure 5 shows similar data for the chemical stability of the $\mathrm{TiN}_{x} / \mathrm{SiO}_{2}$ interface subjected to RTA treatments up to $850^{\circ} \mathrm{C}$. No dramatic changes are observed in the AES spec- 


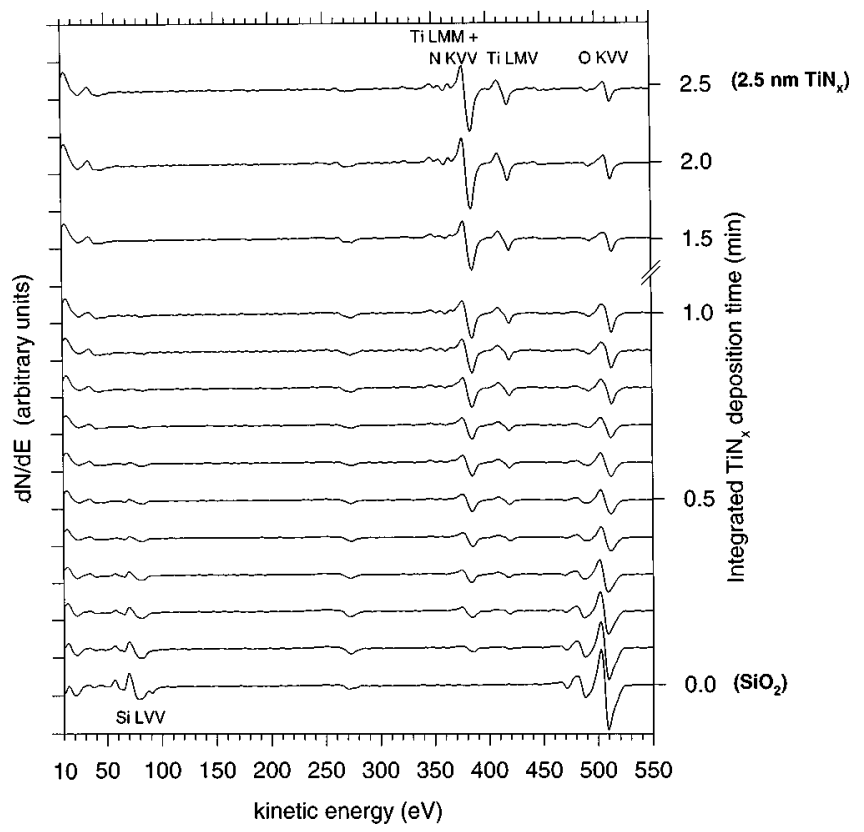

FIG. 3. Interrupted growth of $\mathrm{TiN}_{x}$ on $\mathrm{SiO}_{2} \cdot \mathrm{Si}_{L V V}$ and $\mathrm{O}_{K V V}$ intensities decrease while $\mathrm{Ti}_{L M M}+\mathrm{N}_{K V V}$ and $\mathrm{Ti}_{L M V}$ peaks increase. $\mathrm{Ti}_{L M M}+\mathrm{N}_{K V V}$ peak at $385 \mathrm{eV}$ and $\mathrm{Ti}_{L M V}$ peak at $420 \mathrm{eV}$ have asymmetric intensities indicating growth of $\operatorname{TiN}_{x}$ without a seed layer.

tra until $850^{\circ} \mathrm{C}$, at which point the $\mathrm{Si}_{L V V}$ intensity increases significantly. In addition, the $\mathrm{O}_{K V V}$ peak is redshifted and increases in intensity, similar to the behavior observed for $\mathrm{WN}_{x}$.

The electrical characteristics of MOS capacitors fabricated with $\mathrm{WN}_{x}$ and $\mathrm{TiN}_{x}$ gate electrodes are presented in

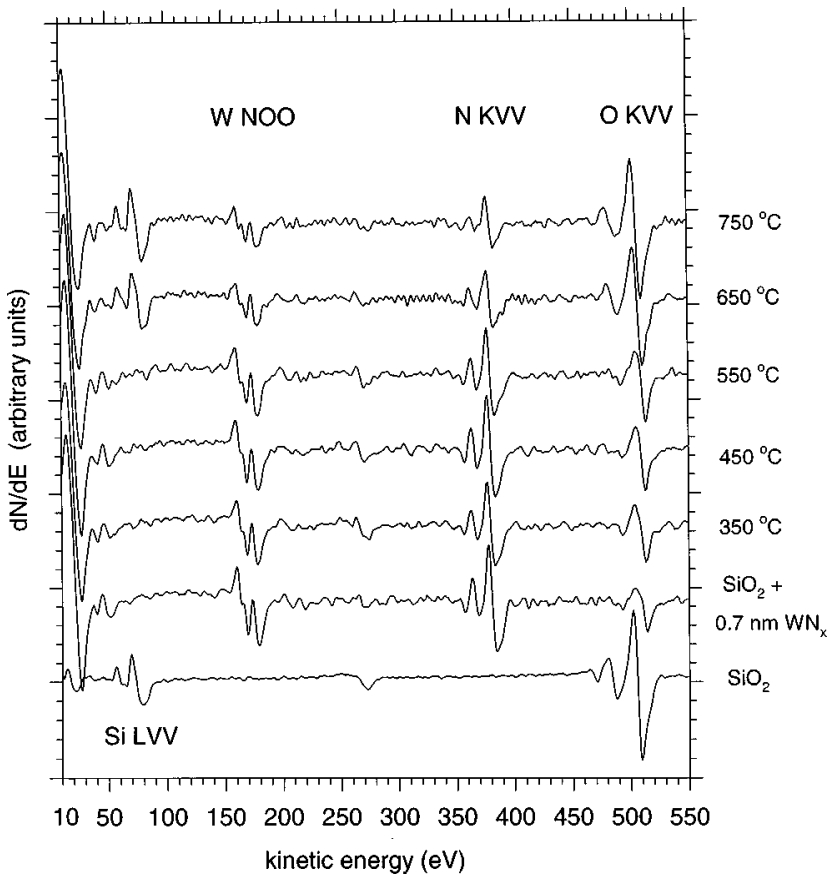

FIG. 4. Chemical stability of the $\mathrm{WN}_{x} / \mathrm{SiO}_{2}$ interface for sequential RTA treatments. $\mathrm{Si}_{L V V}$ reappears and $\mathrm{O}_{K V V}$ redshifts above $650{ }^{\circ} \mathrm{C}$, indicating the oxide has been re-exposed.

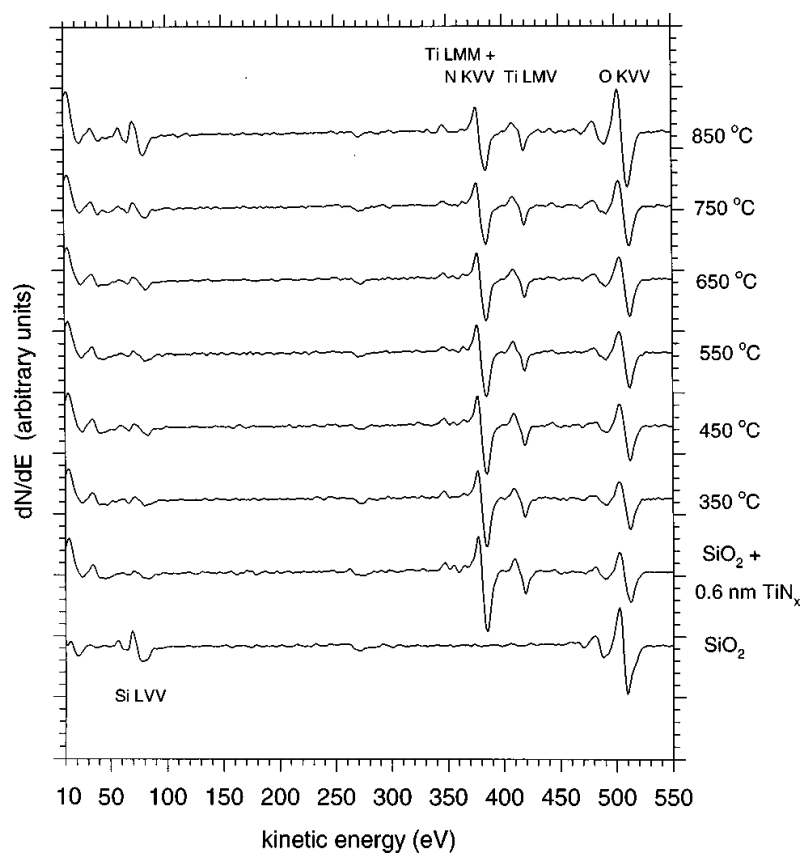

FIG. 5. Chemical stability of the $\operatorname{TiN}_{x} / \mathrm{SiO}_{2}$ interface for sequential RTA treatments. $\mathrm{Si}_{L V V}$ increases and $\mathrm{O}_{K V V}$ redshifts above $850{ }^{\circ} \mathrm{C}$, indicating the oxide has been re-exposed.

Figs. 6 and 7. In Fig. 6, quasistatic and high-frequency $C-V$ data for both composite metal gate electrodes show good electrical characteristics with densities of interface traps, $D_{\text {it }}<2 \times 10^{11} \mathrm{~cm}^{-2} \mathrm{eV}^{-1}$. The capacitors fabricated with a $\operatorname{TiN}_{x}$ gate display a flatband voltage that is $0.47 \mathrm{eV}$ lower

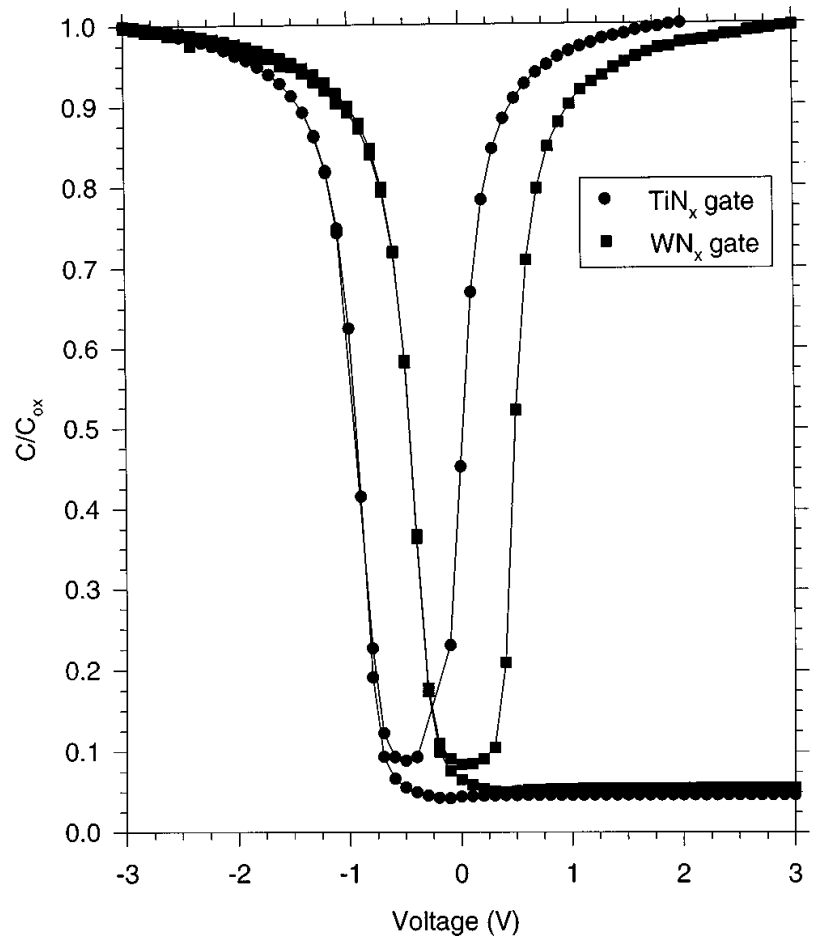

FIG. 6. High-frequency and quasistatic $C-V$ curves for MOS capacitors using $\mathrm{WN}_{x}$ and $\mathrm{TiN}_{x}$ gates. The flatband voltage for the $\mathrm{TiN}_{x}$ devices is 0.47 $\mathrm{eV}$ lower than the $\mathrm{WN}_{x}$ capacitors. 


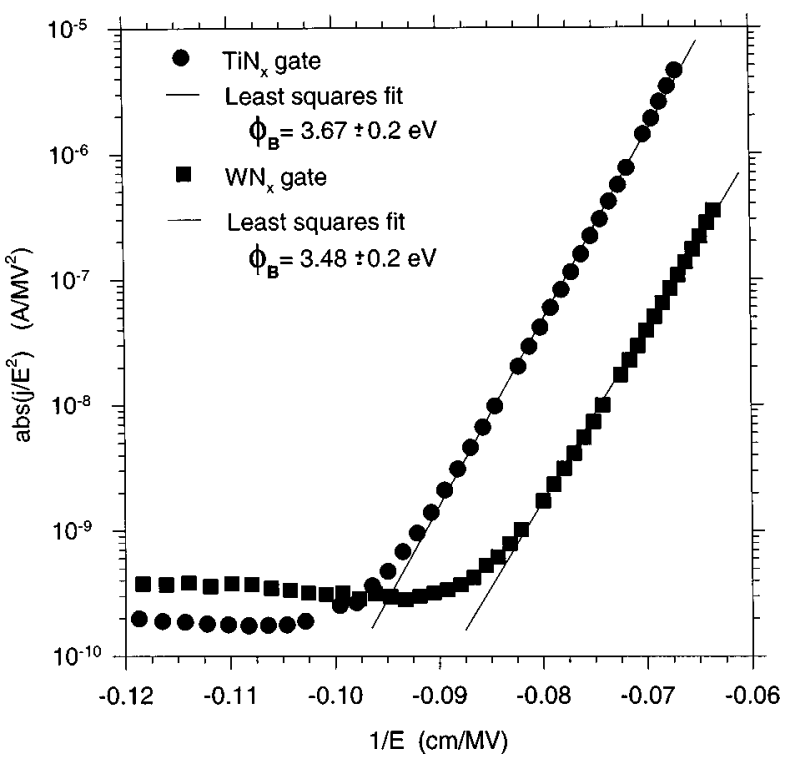

FIG. 7. Fowler-Nordheim plot of tunneling current for MOS capacitors using $\mathrm{WN}_{x}$ and $\mathrm{TiN}_{x}$ gates. Least-squares fits give barrier heights of $\Phi_{B}$ $=3.48 \pm 0.2 \mathrm{eV}$ and $\Phi_{B}=3.67 \pm 0.2 \mathrm{eV}$, respectively.

than those using a $\mathrm{WN}_{x}$ gate. A Fowler-Nordheim plot of the tunneling current is exhibited in Fig. 7 for both gate metals along with least-squares fits to the data. From the slopes of these fits, barrier heights with respect to $\mathrm{SiO}_{2}$ of $\Phi_{B}=3.48 \pm 0.2 \mathrm{eV}$ for $\mathrm{WN}_{x}$ and $\Phi_{B}=3.67 \pm 0.2 \mathrm{eV}$ for $\mathrm{TiN}_{x}$ are calculated assuming an effective-mass $m^{*}=0.5 m_{e} \cdot{ }^{20}$

\section{DISCUSSION}

The initial formation of the $\mathrm{WN}_{x} / \mathrm{SiO}_{2}$ interface seen in Fig. 2 shows the presence of both $\mathrm{W}_{N O O}$ and $\mathrm{N}_{K V V}$ features indicating that the compound metal grows directly on $\mathrm{SiO}_{2}$ without the need for an intervening metallic seed or template layer. Similarly, comparing the asymmetric intensities of the peaks at 385 and $420 \mathrm{eV}$ for the initial $\mathrm{TiN}_{x}$ layers in Fig. 3 with the bulk Ti and $\mathrm{TiN}_{x}$ spectra shown in Fig. 1, it is clear that $\mathrm{TiN}_{x}$ growth on $\mathrm{SiO}_{2}$ also proceeds without a seed layer. Both figures show the $\mathrm{Si}_{L V V}$ peak intensity decreasing as the metal layer grows and the interface is effectively buried by about $0.8 \mathrm{~nm}$ of metal. This thickness is consistent with the escape depth of $\sim 0.6 \mathrm{~nm}$ for Auger electrons at the $\mathrm{Si}_{L V V}$ energy of $\sim 90 \mathrm{eV} .^{21}$ The gradual blueshift of the $\mathrm{O}_{K V V}$ peak from the position characteristic of $\mathrm{SiO}_{2}$ to that of the metal oxide is also consistent with the interface being buried. For both compound metals, bulklike spectra are observed once the thickness is greater than 1.5-2.0 nm.

Turning to the RTA data, the reappearance of the $\mathrm{Si}_{L V V}$ peak in Fig. 4 after annealing at $650{ }^{\circ} \mathrm{C}$ indicates that a change has occurred in the metal film which re-exposes the $\mathrm{WN}_{x} / \mathrm{SiO}_{2}$ interface. This conclusion is supported by the redshift of the $\mathrm{O}_{K V V}$ peak from the metal-oxide energy back to the position characteristic of $\mathrm{SiO}_{2}$. This change may be the result of a chemical reaction between the metal film and the dielectric or it may result from a change in the physical properties of the film such as crystallization and grain growth. ${ }^{22}$ Similar behavior is observed in Fig. 5 for the $\mathrm{TiN}_{x} / \mathrm{SiO}_{2}$ interface, except in this case changes in the AES spectrum do not occur until the sample is annealed at $850^{\circ} \mathrm{C}$. The $\mathrm{Si}_{L V V}$ and $\mathrm{O}_{K V V}$ peak intensities grow and the latter is redshifted, indicating that Auger electrons from the interface region are being detected. For both composite metals, further study is needed to elucidate the details of these changes and to determine the final composition and structures that result. It is also unclear if these metal/ $/ \mathrm{SiO}_{2}$ interfaces are stable above their respective threshold temperature for shorter duration anneals, which would be expected if the changes are controlled by kinetics.

Finally, the MOS capacitors made with $\mathrm{WN}_{x}$ and $\mathrm{TiN}_{x}$ gate electrodes shown in Figs. 6 and 7 exhibit excellent device characteristics. The density of interface traps, $D_{\text {it }}<2 \times 10^{11} \mathrm{~cm}^{-2} \mathrm{eV}^{-1}$ for both $\mathrm{TiN}_{x}$ and $\mathrm{WN}_{x}$ indicate deposition of the gate metal has not affected the underlying $\mathrm{Si} / \mathrm{SiO}_{2}$ interface. The flatband voltage shift observed between the $C-V$ curves of Fig. 6 suggests the $\mathrm{WN}_{x} / \mathrm{SiO}_{2}$ barrier height is larger than $\mathrm{TiN}_{x} / \mathrm{SiO}_{2}$. Since these wafers were processed in parallel and received the same treatment at each step except for the gate metal deposition, it is assumed that the flatband voltage shift due to fixed positive charge, etc., is the same for both samples. The observed flatband voltage shift should be a direct measure of the difference in barrier height for the two metals. The $\mathrm{WN}_{x} / \mathrm{SiO}_{2}$ and $\mathrm{TiN}_{x} / \mathrm{SiO}_{2}$ barrier heights determined from Fowler-Nordheim tunneling, $\Phi_{B}=3.48 \pm 0.2 \mathrm{eV}$ and $\Phi_{B}=3.67 \pm 0.2 \mathrm{eV}$, respectively, include substantial corrections to properly account for the flatband voltage and potential drop in the substrate. Although the barrier height for $\mathrm{WN}_{x}$ is not internally consistent with the $C-V$ results, these values generally agree with similar measurements made by other authors. ${ }^{12,15}$

The $\mathrm{TiN}_{x} / \mathrm{SiO}_{2}$ barrier height places the Fermi-level $E_{F}$ for $\mathrm{TiN}_{x}$ near midgap in $\mathrm{Si}$, making it unsuitable for CMOS applications because its large threshold voltage $V_{t}$ is unacceptable. However, the $C-V$ data indicate $E_{F}$ for $\mathrm{WN}_{x}$ lies closer to the valence band, resulting in an attractive $V_{t}$ for $n$ MOS devices. In addition, if it is possible to modify the work function of these compound metals by depositing an appropriate metal overlayer such as $\mathrm{W},{ }^{12-15}$ then they may be incorporated as a reaction barrier in advanced gate stack designs.

\section{CONCLUSIONS}

The compound metals $\mathrm{WN}_{x}$ and $\mathrm{TiN}_{x}$ are promising candidates for use in future CMOS engineered gate stack designs. Both materials grow on $\mathrm{SiO}_{2}$ without a seed layer and films as thin as $0.8 \mathrm{~nm}$ are chemically stable below $650{ }^{\circ} \mathrm{C}$ for $\mathrm{WN}_{x}$ or $850{ }^{\circ} \mathrm{C}$ for $\mathrm{TiN}_{x}$. MOS capacitors made using $\mathrm{WN}_{x}$ and $\mathrm{TiN}_{x}$ gates display good quasistatic and highfrequency $C-V$ characteristics with low interface trap densities, $D_{\text {it }}<2 \times 10^{11} \mathrm{~cm}^{-2} \mathrm{eV}^{-1}$. The observed shift in flatband voltage indicates the Fermi level lies near the $\mathrm{Si}$ midgap for $\mathrm{TiN}_{x}$ and closer to the valence band for $\mathrm{WN}_{x}$. 


\section{ACKNOWLEDGMENTS}

The authors would like to thank Hanyang Yang for his assistance in preparing the MOS capacitors and Dr. George Brown for helpful discussions. This work is supported by ONR, NSF, ERC, and SRC.

${ }^{1}$ R. H. Dennard, F. H. Gaensslen, H.-N. Yu, V. L. Rideout, E. Bassous, and A. R. LeBlanc, IEEE J. Solid-State Circuits SC-9, 256 (1974).

${ }^{2}$ G. Bacarani, M. R. Wordeman, and R. H. Dennard, IEEE Trans. Electron Devices ED-31, 452 (1984)

${ }^{3}$ J. R. Brews, W. Fichtner, E. H. Nicollian, and S. M. Sze, IEEE Trans. Electron Devices EDL-1, 2 (1980).

${ }^{4}$ J. R. Brews, K. K. Ng, and R. K. Watts, in Submicron Integrated Circuits, edited by R. K. Watts (Wiley Interscience, New York, 1989), pp. 23-37. ${ }^{5}$ S. Q. Wang and J. W. Mayer, J. Appl. Phys. 64, 4711 (1988).

${ }^{6} \mathrm{R}$. Pretorius, J. M. Harris, and M-A. Nicolet, Solid-State Electron. 21, 667 (1978).

${ }^{7}$ M. Wittmer, J. R. Noser, and H. Melchior, J. Appl. Phys. 54, 1423 (1983).

${ }^{8}$ M. Wittmer and H. Melchior, Thin Solid Films 93, 397 (1982).

${ }^{9}$ D. H. Lee, K. H. Yeom, M. H. Cho, N. S. Kang, and T. E. Shim, Proceedings of the 1996 Symposium on VLSI Tech. (IEEE, Piscataway, NJ, 1996), pp. 208-209.
${ }^{10}$ D. H. Lee, S. H. Joo, G. H. Lee, J. Moon, T. E. Shim, and J. G. Lee, Proceedings of the 1995 Symposium on VLSI Tech. (IEEE, Piscataway, NJ, 1995), pp. 119-120.

${ }^{11}$ K. T. Kim, L. G. Kang, T. S. Park, Y. S. Shin, J. K. Park, C. J. Lee, C. G. Hwang, D. Chin, and Y. E. Park, Proceedings of the 1990 Symposium on VLSI Tech. (IEEE, New York, 1990), p. 115-116.

${ }^{12}$ H. Yang et al., Tech. Dig. Int. Electron Devices Meet. 459 (1997).

${ }^{13}$ A. Chatterjee et al., Tech. Dig. Int. Electron Devices Meet. 821 (1997).

${ }^{14}$ J. C. Hu et al., Tech. Dig. Int. Electron Devices Meet. 825 (1997).

${ }^{15} \mathrm{G}$. A. Brown, Presented at the SRC Topical Research Conference on Advanced Gate Dielectrics: Scaled $\mathrm{SiO}_{2}$ and Alternative Dielectrics, Austin, TX, Oct. 1997 (unpublished).

${ }^{16}$ W. Pamler, Surf. Interface Anal. 13, 55 (1988).

${ }^{17}$ A. J. Perry, C. Strandberg, W. D. Sproul, S. Hoffmann, C. Ernsberger, J. Nickerson, and L. Chollet, Thin Solid Films 153, 169 (1987).

${ }^{18}$ B. J. Burrow, A. E. Morgan, and R. C. Ellwanger, J. Vac. Sci. Technol. A 4, 2463 (1986).

${ }^{19}$ P. T. Dawson and K. K. Tzatzov, Surf. Sci. 149, 105 (1985).

${ }^{20}$ H. Y. Yang, H. Niimi, and G. Lucovsky, J. Appl. Phys. 83, 2327 (1998).

${ }^{21}$ M. P. Seah and W. A. Dench, Surf. Interface Anal. 1, 2 (1979).

${ }^{22}$ B. H. Kear, L. Wu, N. C. Angastiniotis, and L. E. McCandlish, in $A d-$ vanced Topics in Materials Science and Engineering, edited by J. L. Morán-López and J. M. Sanchez (Plenum, New York, 1993), p. 315. 